\title{
Epidemiological and Clinical Aspects of Skin Bleaching in Secondary School in Bohicon, Benin
}

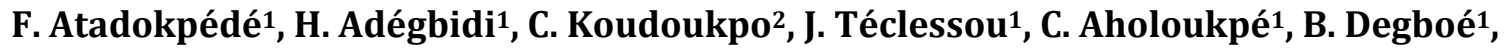 \\ F. do Ango-Padonou' ${ }^{1}$, H. Yedomon ${ }^{1}$ \\ ${ }^{1}$ Faculté des Sciences de la Santé, Cotonou, Bénin \\ ${ }^{2}$ Faculté de Médecine, Université de Parakou, Parakou, Bénin \\ Email: fatadokpede2009@yahoo.fr
}

Received 17 January 2015; accepted 1 February 2015; published 4 February 2015

Copyright (C 2015 by authors and Scientific Research Publishing Inc.

This work is licensed under the Creative Commons Attribution International License (CC BY). http://creativecommons.org/licenses/by/4.0/

(c) (i) Open Access

\section{Abstract}

Skin bleaching is a public health problem in West Africa most studied in general population. We conducted a cross-sectional survey to evaluate the prevalence of the phenomenon in secondary schools in central Benin. The prevalence of voluntary depigmentation (VD) was $36.6 \%$. The sex ratio was 0.49. Gender was statistically associated with VD (p value $<0.000)$. Bleaching products used were often hydroquinone $(42.2 \%)$, and corticosteroid $(22.7 \%)$. The mean duration of the practice was 20 months. Products were applied over all body twice a day in most students. The main dermatological complications of the practice were discoloration $(32.2 \%)$, stretch marks (20\%), acne (18.5\%), and fungal infections (13.1\%). Parents funded and chose the bleaching products in most cases. This was the first survey conducted in secondary schools in West Africa targeted voluntary depigmentation. The high prevalence of the practice raises some questions, among them the core values of West African societies.

\section{Keywords}

Skin Bleachning, Schools, Benin

\section{Introduction}

Voluntary depigmentation (VD) is a practice of using drugs or any other products with a depigmenting potential for cosmetic purposes. The aim of this practice is to obtain a reduction of the physiological skin pigmentation. Reported in the literature in the late sixties, the VD seems to have developed in the modern era with the market- 
ing of topical steroids and compounds with hydroquinone. This is a relatively old and widespread practice in Black Africa. The term voluntary depigmentation is often used in the literature to put special emphasis on its intentional aspect.

VD is a female practice in Africa with prevalence ranging from 25\% to 67\% [1]-[4] in West Africa. This social phenomenon has mainly been described in adults. Studies on the VD in school are rare. The objective of this study was to investigate the epidemiological and clinical aspects of VD in school in central Benin.

\section{Population and Methods}

We conducted a descriptive and analytical cross-sectional study on a sample of students in public and private Colleges of General Education (CEG) in Bohicon, a city in central Benin. Students aged at least 15 years were included.

The town has 6 public and 9 private colleges. A college was used for pre-test and the other for the actual survey. We used a random sampling method in three steps:

-In the first stage a simple random sampling without replacement of $40 \%$ for public institutions and $60 \%$ for private institutions was conducted;

-In the second step, $50 \%$ of classes in selected schools were drawn by simple random sampling without replacement;

-In the third step, the selection of students was done by systematic random sampling. The sampling interval is calculated by dividing the total number of pupils in classes used by the sample size. We used the random number table for the selection of the first student. The other students were drawn systematically by adding the sampling interval to the random number selected.

Students selected were subjected to a pre-questionnaire and were examined by a dermatologist.

The data were recorded and analyzed using Epi Info 3.5.1.

The following statistical tests were used for the description of variables: mean, standard deviation, extreme values, proportion, chi-square test.

The ethical rules were followed by requesting a free and informed consent of the students, an administrative authorization to college principals and parental permission.

\section{Results}

Based on sampling, 429 students were selected and all agreed to participate in the study.

Of the 429 students surveyed and examined 157 practiced voluntary depigmentation. The prevalence of VD was $36.6 \%$ among school students in Bohicon.

Sixty-six point nine percent (66.9\%) of students practicing VD were female and 33.1\% male. The sex ratio was 0.49 . Female gender was statistically associated with the VD in students ( $p$ value $<0.000$ ).

The average age of students who practiced voluntary depigmentation was 18 years with a range of 18 to 27 years.

Thirty-eight point two percent (38.2\%) of students practicing VD were in high school, 36.9\% (p $=0.29)$ were in first class and $24.8 \%(\mathrm{p}=0.02)$ in twelfth grade.

Voluntary depigmentation was also common among students living in monogamous households (43.3\%) than in polygamous households (42.7\%). Only $14 \%$ of students living in homes whose parents are divorced or widowed practiced VD.

In our study, $86.6 \%$ of students practicing VD were Christians, 7\% were Muslims and 6.4\% practiced other religions.

\subsection{Bleaching Agents Used by Students}

Products containing hydroquinone were the most used (42.0\%) followed by corticosteroids (22.7\%) (Table 1).

\subsection{Description of the Practice and Motivation}

The average duration of use of bleaching agents among students was 20 months with a range of 1 - 98 months. The products were applied all over the body by $82.9 \%$ of females (Table 2).

Application was twice daily in $76.2 \%$ of women and $53.8 \%$ of men. It was daily in $25 \%$ of men and $21.9 \%$ of 
Table 1. Skin bleaching products used by school children in central Benin.

\begin{tabular}{cc}
\hline Products & Proportion (\%) \\
Hydroquinone & 42.0 \\
Corticosteroid & 22.3 \\
Mercury compounds & 19.7 \\
Fruit acids & 13.6 \\
Others & 2.3 \\
Total & 100 \\
\hline
\end{tabular}

Table 2. Areas of application of skin bleaching products by school children in central Benin.

\begin{tabular}{ccc}
\hline & \multicolumn{3}{c}{ Sex } \\
Areas of application & Male (\%) & Female (\%) \\
\cline { 2 - 3 } & $21(40.4)$ & $18(17.1)$ \\
Face & $31(59.6)$ & $87(82.9)$ \\
Tll body & $\mathbf{5 2 ( 1 0 0 )}$ & $\mathbf{1 0 5}(\mathbf{1 0 0})$ \\
\hline
\end{tabular}

women. A weekly application was made in $21.1 \%$ of men and $1.9 \%$ of women. The mean monthly cost of products was 2.6 US dollars with a range of 0.7 dollars to 10 dollars. It was supported by parents (70.1\%), friends (26.8\%), and others (3.1). The choice of depigmenting cosmetics was made by the parents in $52.2 \%$ of cases, by the students themselves in $33.8 \%$ of cases and by friends in $14 \%$ of cases.

Motivations at the beginning of practice were aesthetic in $78.1 \%$ of girls and those evoked to continue the practice were looking for light-skin at 76.2\% (Table 3).

The attitude of parents and friends in relation to the practice was encouraging in $57.6 \%$ of girls and $44.3 \%$ boys. However, $32.4 \%$ of parents of girls and $40 \%$ of parents of boys were indifferent. The opposition of parents to voluntary depigmentation was noted in $10 \%$ of cases in girls and $15.7 \%$ of boys.

\subsection{Dermatological Complications}

Discolorations were observed in 32.3\% of students practicing VD (Table 4).

Superficial fungal infections were the most frequent infectious complications. They sat on the cheeks, arms, legs or internal surfaces of the body.

\subsection{Knowledge of the Dangers of Depigmentation by Students}

The assessment of knowledge of users showed that $98.7 \%$ of students were unaware of the harmful effects of the practice.

\section{Discussion}

After our investigation, we were able to determine the epidemiological profile of the VD in schools in Bohicon.

The method based on random sampling of school population allows us to say that our results are valid.

The prevalence of VD was high in school in central Benin since it concerned 36.6\% of students of public and private schools. To our knowledge this is the first study assessing the prevalence of VD in schools in West Africa. Other studies in the general population in West Africa reported a high prevalence of the phenomenon:

$-5 \%$ in the study by Mahe [1] involving 210 adult women in the general population in Mali;

$-58.7 \%$ in the study of Nnoruka [5] in the general adult population in Nigeria;

$-59 \%$ of the 910 women in the study by Pitche [3] in Togo;

$-67 \%$ of women in the investigation by Wone in Dakar [4]. 
Table 3. Motivations of voluntary depigmentation among school children in Benin.

\begin{tabular}{|ccc}
\hline Motivations & Male & Sex \\
\cline { 2 - 3 } Motivations at the beginning & & Female \\
Skin defect & $20(38.5)$ & $23(21.9)$ \\
Aesthetic & $32(61.5)$ & $83(78.1)$ \\
Motivations to continue & & $27(76.2)$ \\
Search for light skin & $13(52.0)$ & $09(01.9)$ \\
Effectiveness & $07(28.0)$ & $09(21.9)$ \\
Fear to become black again & $05(20.0)$ & $31(51.7)$ \\
Motivations to stop & & $14(23.3)$ \\
Health disorders & $13(48.1)$ & $15(25.0)$ \\
Lack of efficacy & $09(33.3)$ & \\
Opposition of parents & $05(18.5)$ & \\
\hline
\end{tabular}

Table 4. Skin disorders observed among school children practicing voluntary depigmentation.

\begin{tabular}{ccc}
\hline Skin disorders & Number & Proportion (\%) \\
\hline Dyschromia & 42 & 32.3 \\
Stretch marks & 26 & 20.0 \\
Acne & 24 & 18.5 \\
Superficial mycosis & 17 & 13.1 \\
Skin atrophy & 17 & 13.1 \\
Contact dermatitis & 04 & 3.0 \\
Total & 130 & 100 \\
\hline
\end{tabular}

Voluntary depigmentation was particularly marked among women in West Africa and various studies have targeted this population [3] [6] [7]. Sixty-six point nine percent (66.9\%) of students practicing VD in our study were female, reflecting the predominance of the practice in teenager. However, the VD was also observed in $26.7 \%$ of men according to a Nigerian study [8]. The practice has also been reported in men in Congo and South Africa [9] [10]. In our study DV was noted in 33.1\% of boys. A search for identity or a desire for seduction in this transition period between adolescence and adulthood may explain the VD in students.

The depigmenting cosmetics principles identified in our study are hydroquinone, steroids and mercury compounds. These products have been reported in previous studies [2] [3] [8]. Normaly these products are for medical use but they are diverted for use as cosmetics. In our study, hydroquinone was the most used (42.0\%). In the opposite mercury compounds were widely used in the study by Pitché et al. in Togo [3], while products with hydroquinone were the most used in the study by Traoré et al. in Burkina Faso [2]. The market availability and the supposed effectiveness of skin-lightening products influence the use of bleaching agents by country.

The practice was for most students a twice-daily application all over the body. The same technique was noted in other studies [1] [3]. Some students preferred product application on the face. This could be related to a search for a more perfect complexion in this open area. The mean monthly cost of the products used by the students was 2.6 US dollars. At this cost, depigmenting cosmetics can be affordable for all and making high prevalence of VD in teenager and maintaining its sustainability.

The bleaching agents were funded in $70.1 \%$ of cases by the parents and the parents were involved in product choice in $52.2 \%$ of cases. It could be parents themselves practicing VD and therefore using these depigmenting cosmetic products for their children since infancy. Parents of students are heavily involved in practice by funding or by providing cosmetic depigmenting to their children. This calls into question the voluntary nature of the 
practice for these students who are still under the authority of parents.

Voluntary depigmentation is motivated initially by a desire to lighten the skin or correct a defect of the skin. These motivations are almost identical to those given in the literature [2] [11]. The practice is in progress because of effectiveness of bleaching agents and fear to become black again. Users seem therefore become dependent on these products as a drug [12]. But the onset of skin complications and the opposition of parents drive to stop the practice. Dyschromias represented $32.2 \%$ of the cutaneous complications observed in our study. These discolorations were also noted in $70.80 \%$ of women in Togo [3]. This pigmentary disorder is a real cosmetic problem for practitioners of VD because of the contrast between clear complexion and black complexion. This is double skin pigmentation with alternating areas of hyperpigmentation and hypopigmentation in the same individual. This dual pigmentation may be due to non-uniform application of the products on the body but also to the presence of physiologically pigmented or previously traumatized and resistant regions. These discolorations may cause a vicious circle with a determination to make them disappear by multiplying the applications or by combining different products. Acne and stretch marks are skin diseases frequently encountered during adolescence which makes it difficult to establish a cause and effect relationship between these conditions and the VD at this age. Nevertheless, $20 \%$ of students practicing VD had stretch marks in our study. The frequency of acne in students practicing VD in our study was $18.5 \%$. This frequency is comparable to that seen in Senegal (19.5\%) [13] but lower than that recorded in Togo (16.17\%) [3].

The infections encountered in our study were fungal infections (13.1\%). These are the most common infections in adults practicing VD. Sometimes unusual facial locations were also described by Mahé et al. [14]. Although our investigation related to high school students, $98.7 \%$ were unaware of the complications associated with the use of these products.

\section{Conclusion}

Voluntary depigmentation in schools in central Benin is a real public health problem. It also poses a problem of loss of core values in favor of artificial values. It is urgent that a true youth outreach program has been settled up to fight against this scourge, which could play a role in poor academic performance. The authors declare no conflict of interest.

\section{References}

[1] Mahe, A., Blanc, L., Halna, J.M., Keita, S., Sanogo, T. and Bobin, P. (1993) An Epidemiologic Survey on the Cosmetic Use of Bleaching Agents by the Women of Bamako, Mali. Annales de Dermatologie et de Vénéréologie, 120, 870-873.

[2] Traoré, A., Kadeba, J.C. and Niamba, P. (2005) Use of Cutaneous Depigmenting Products by Women in Two Towns in Burkina Faso: Epidemiologic Data, Motivations, Products and Side Effects. International Journal of Dermatology, 44, 30-32. http://dx.doi.org/10.1111/j.1365-4632.2005.02807.x

[3] Pitché, P., Afanou, A., Amanga, Y. and Tchangai-Walla, K. (1998) Les pratiques cosmétiques dépigmentantes des femmes à Lomé (Togo). Medecine d'Afrique Noire, 45, 709-713.

[4] Wone, I., Tal-Dia, A., Diallo, O.F., Badiane, M., Touré, K. and Diallo, I. (2000) Prévalence de l'utilisation de produits cosmétiques dépigmentants dans deux quartiers à Dakar (Sénégal). Dakar Médical, 45, 154-157.

[5] Nnoruka, E. and Okoye, O. (2006) Tropical Steroid Abuse: Its Use as a Depigmenting Agent. Journal of the National Medical Association, 98, 934-939.

[6] Del Giudice, P. and Yves, P. (2002) The Widespread Use of Skin Lightening Creams in Senegal: A Persistent Public Health Problem in West Africa. International Journal of Dermatology, 41, 69-72. http://dx.doi.org/10.1046/j.1365-4362.2002.01335.x

[7] Morand, J.J., Ly, F., Lightburn, E. and Mahé, A. (2007) Complications de la dépigmentation cosmétique en Afrique. Medecine Tropicale, 67, 627-634.

[8] Adebajo, S.B. (2002) An Epidemiological Survey of the Use of Cosmetic Skin Lightening Cosmetics among Traders in Lagos Nigeria. West African Journal of Medicine, 21, 51-55.

[9] Hardwick, N., Van Gelger, L.W., Van der Merwe, C.A. and Van der Merwe, M.P. (1989) Exogenous Ochronosis: An Epidemiological Study. British Journal of Dermatology, 120, 229-238. http://dx.doi.org/10.1111/j.1365-2133.1989.tb07787.x

[10] Didillon, H. and Bounsana, D. (1986) Modifier la couleur de sa peau: Mode ou complexe? Acte du colloque de Brazzaville, Karthala, 255-283. 
[11] Muchadeyi, E., Thompson, S. and Baker, N. (1983) A Survey of the Constituents, Availability and Use of Skin Lightening Creams in Zimbabwe. Central African Journal of Medicine, 29, 225-227.

[12] Ly, F., Mahé-Vasseur, P., Agne El Fecky, A. and Verschoore, M. (2007) Enquête qualitative sur la dépigmentation artificielle de la peau noire: Essai d'analyse anthropologique et psychosociale en contexte sénégalais. Annales de Dermatologie et de Vénéréologie, 134, 21-22.

[13] Raynaud, E., Cellier, C. and Perret, J.L. (2001) Dépigmentation cutanée à visée cosmétique: Enquête de prévalence et effets indésirables dans une population féminine Sénégalaise. Annales de Dermatologie et de Vénéréologie, 128, 720724.

[14] Mahe, A., Ly, F., Aymard, G. and Dangou, J.M. (2003) Skin Diseases Associated with the Cosmetic Use of Bleaching Products in Women from Dakar, Sénégal. British Journal of Dermatology, 148, 493-500.

http://dx.doi.org/10.1046/j.1365-2133.2003.05161.x 
Scientific Research Publishing (SCIRP) is one of the largest Open Access journal publishers. It is currently publishing more than 200 open access, online, peer-reviewed journals covering a wide range of academic disciplines. SCIRP serves the worldwide academic communities and contributes to the progress and application of science with its publication.

Other selected journals from SCIRP are listed as below. Submit your manuscript to us via either submit@scirp.org or Online Submission Portal.
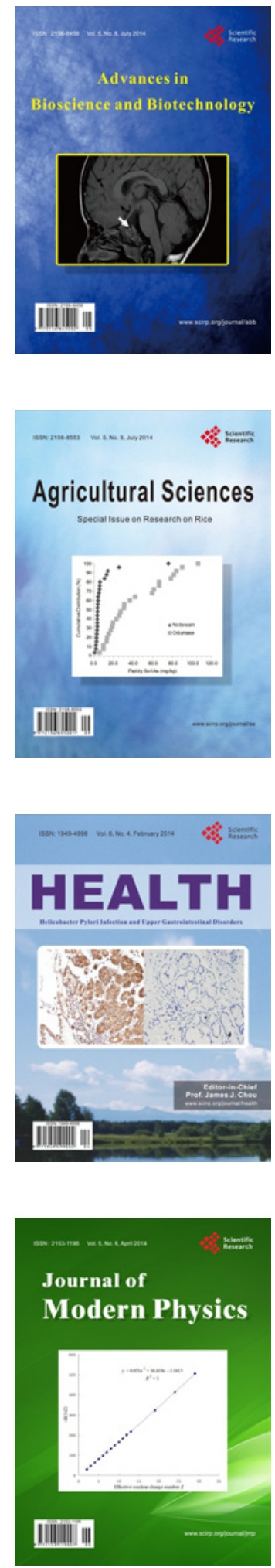
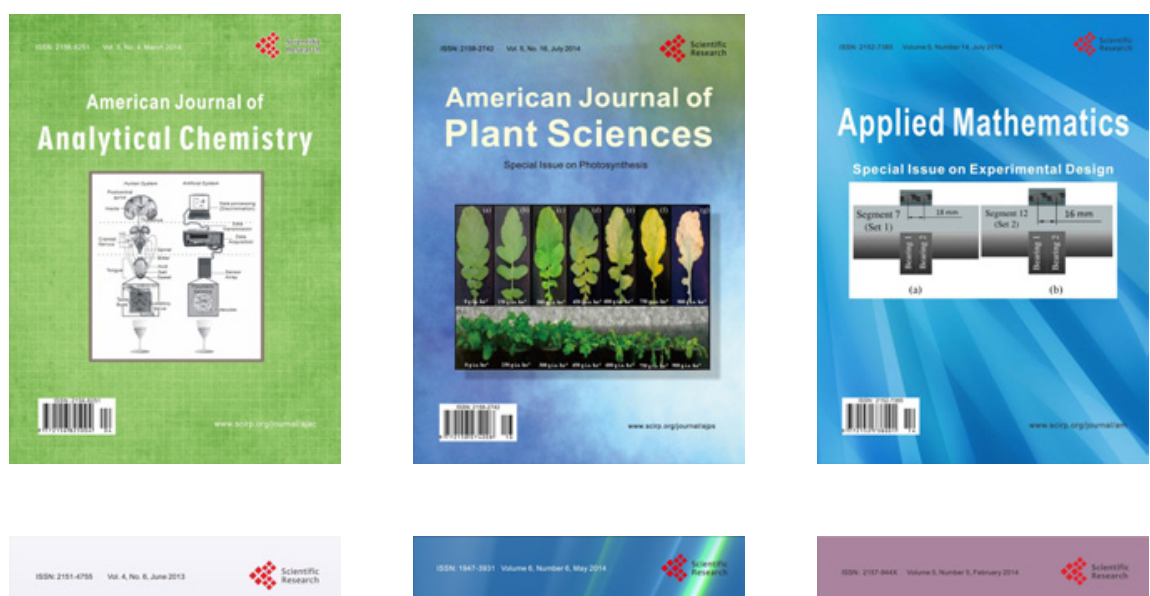

Creative Education
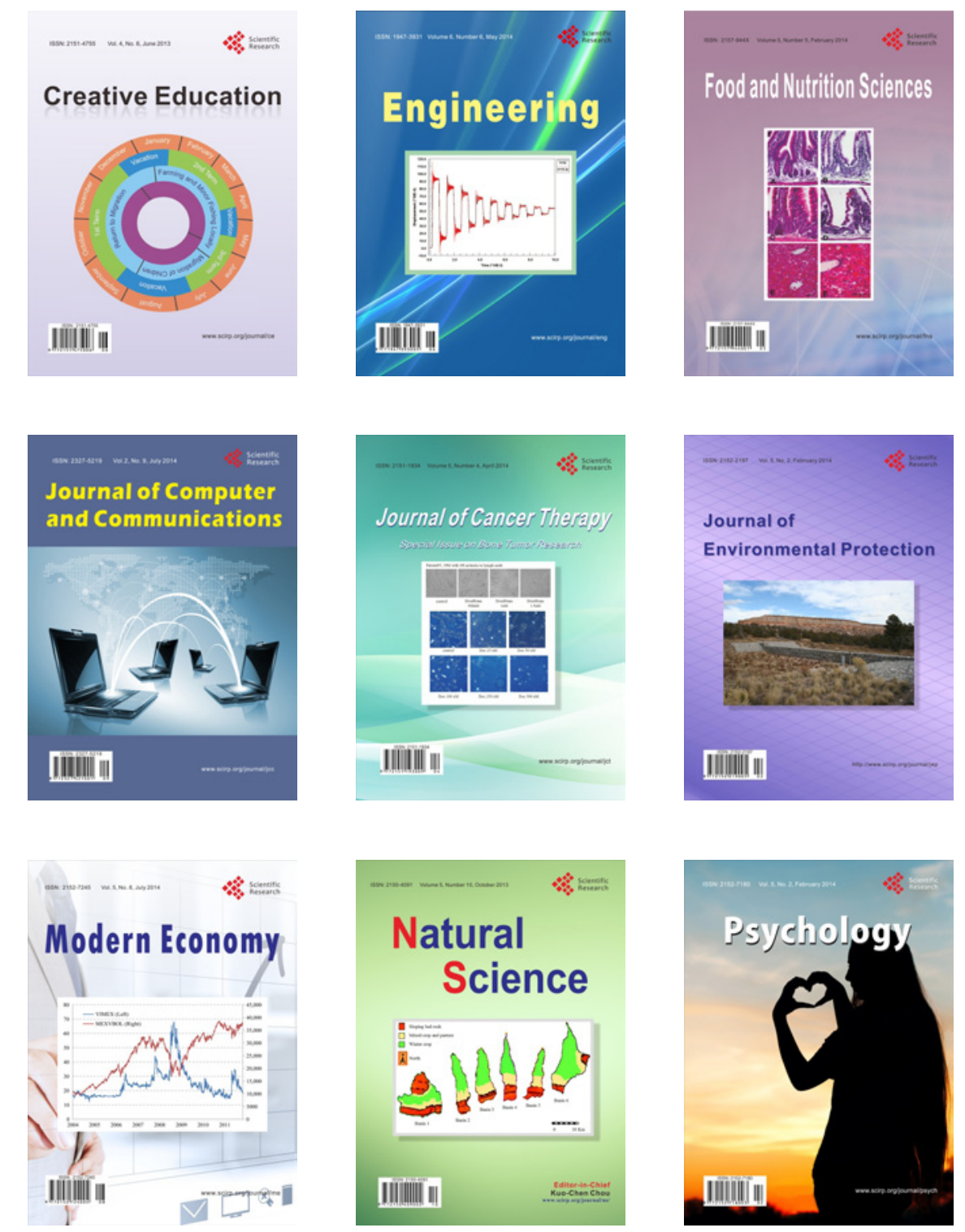